\title{
Pan-Continental Droughts in North America over the Last Millennium*
}

\author{
BENJAMIN I. COOK \\ NASA Goddard Institute for Space Studies, New York, and Lamont-Doherty Earth Observatory, Palisades, New York \\ JASON E. SMERdon, RichARD SEAGER, AND EDWARD R. COOK \\ Lamont-Doherty Earth Observatory, Palisades, New York
}

(Manuscript received 14 February 2013, in final form 22 July 2013)

\begin{abstract}
Regional droughts are common in North America, but pan-continental droughts extending across multiple regions, including the 2012 event, are rare relative to single-region events. Here, the tree-ring-derived North American Drought Atlas is used to investigate drought variability in four regions over the last millennium, focusing on pan-continental droughts. During the Medieval Climate Anomaly (MCA), the central plains (CP), Southwest (SW), and Southeast (SE) regions experienced drier conditions and increased occurrence of droughts and the Northwest (NW) experienced several extended pluvials. Enhanced MCA aridity in the SW and CP manifested as multidecadal megadroughts. Notably, megadroughts in these regions differed in their timing and persistence, suggesting that they represent regional events influenced by local dynamics rather than a unified, continental-scale phenomena. There is no trend in pan-continental drought occurrence, defined as synchronous droughts in three or more regions. SW, CP, and SE $(\mathrm{SW}+\mathrm{CP}+\mathrm{SE})$ droughts are the most common, occurring in $12 \%$ of all years and peaking in prevalence during the twelfth and thirteenth centuries; patterns involving three other regions occur in about $8 \%$ of years. Positive values of the Southern Oscillation index (La Niña conditions) are linked to SW, CP, and SE (SW+CP+SE) droughts and SW, CP, and NW $(\mathrm{SW}+\mathrm{CP}+\mathrm{NW})$ droughts, whereas $\mathrm{CP}, \mathrm{NW}$, and $\mathrm{SE}(\mathrm{CP}+\mathrm{NW}+\mathrm{SE})$ droughts are associated with positive values of the Pacific decadal oscillation and Atlantic multidecadal oscillation. While relatively rare, pancontinental droughts are present in the paleo record and are linked to defined modes of climate variability, implying the potential for seasonal predictability. Assuming stable drought teleconnections, these events will remain an important feature of future North American hydroclimate, possibly increasing in their severity in step with other expected hydroclimate responses to increased greenhouse gas forcing.
\end{abstract}

\section{Introduction}

During the summer of 2012, over half of the continental United States experienced moderate-to-severe drought conditions, with the core of the drought area extending across Mexico and the desert Southwest, the central plains, and the southeastern United States (Fig. 1). At its peak in July, the drought covered $61.8 \%$ of the contiguous United States (NCDC 2013a), exceeding the 99th percentile of drought-covered area observed during

\footnotetext{
* Lamont-Doherty Earth Observatory Contribution Number 7730.

Corresponding author address: Benjamin I. Cook, NASA Goddard Institute for Space Studies, 2880 Broadway, New York, NY 10025.

E-mail: benjamin.i.cook@nasa.gov
}

the full period of observation (from 1895 to the present). Notably, the area of the United States classified by the National Climatic Data Center (NCDC) as "moderately to extremely dry" exceeded the July 2012 area in only eight other months during the instrumental record (see http://www1.ncdc.noaa.gov/pub/data/cmb/sotc/drought/ 2012/13/uspctarea-wetdry-mod.txt): April-October 1934 and December 1939, all during the Dust Bowl drought of the 1930s.

Drought is a common and recurrent feature of North American climate (e.g., Cook et al. 2007; McCabe et al. 2004; Nigam et al. 2011; Schubert et al. 2004a,b; Seager et al.2005), but pan-continental droughts like the drought of 2012 are rare relative to single-region events. Despite their rarity, however, these events present significant management challenges because they range across broad regions and communities with different water resource constraints (e.g., irrigation from rivers versus groundwater), 


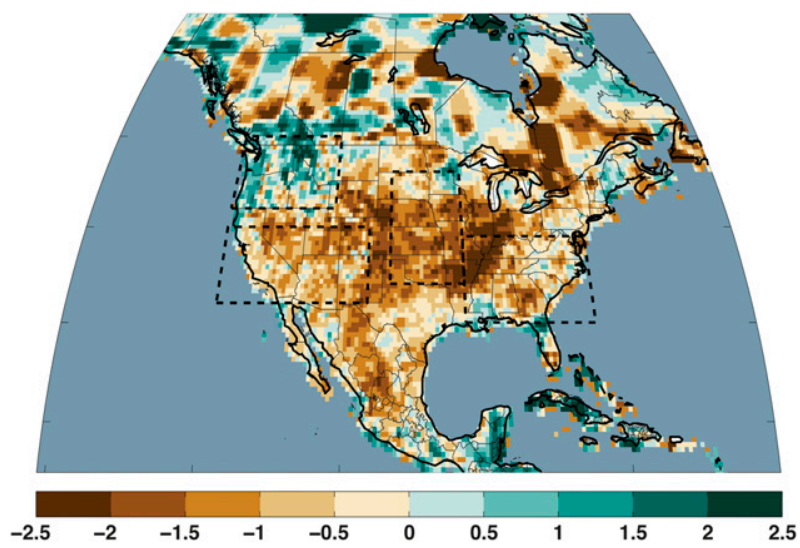

FIG. 1. Model-estimated JJA standardized soil moisture anomalies for 2012, from the CPC (Fan and van den Dool 2004). Base period for the standardization was 1948-2012. Analyzed drought regions in this study are outlined by the black dashed lines. The regions are defined as the southwest $\left(\mathrm{SW} ; 32^{\circ}-40^{\circ} \mathrm{N}, 125^{\circ}-105^{\circ} \mathrm{W}\right)$, central plains $\left(\mathrm{CP} ; 34^{\circ}-46^{\circ} \mathrm{N}, 102^{\circ}-92^{\circ} \mathrm{W}\right)$, northwest $\left(\mathrm{NW} ; 42^{\circ}-\right.$ $\left.50^{\circ} \mathrm{N}, 125^{\circ}-110^{\circ} \mathrm{W}\right)$, and southeast $\left(\mathrm{SE} ; 30^{\circ}-39^{\circ} \mathrm{N}, 92^{\circ}-75^{\circ} \mathrm{W}\right)$.

ecosystems (e.g., forests and grasslands), and crops. The spatially extensive nature of pan-continental droughts also makes understanding their dynamics difficult. By definition, they encompass geographically broad regions of North America with often widely different climates, seasonalities, and climate mode teleconnections. Droughts in the Southwest, for example, are typically caused by winter and early spring precipitation deficits forced by cold sea surface temperature (SST) anomalies in the eastern tropical Pacific (e.g., Herweijer et al. 2006; Hoerling et al. 2009; Schubert et al. 2009; Seager et al. 2005). The Northwest has similarly strong Pacific SST teleconnections, but of opposite sign, resulting in hydroclimate anomalies that are often out of phase with the Southwest (McCabe et al. 2004, 2008; Steinman et al. 2012). The central plains region, while still influenced to some degree by the Pacific (Schubert et al. 2004a,b), is on the northern edge of the Pacific SST teleconnection, and droughts in this area are driven primarily by spring and summer precipitation reductions often linked to warm Atlantic SSTs (e.g., Kushnir et al. 2010; Nigam et al. 2011). Much like the central plains, droughts in the southeastern United States also respond to Atlantic and Pacific SST variations (Mo and Schemm 2008; Pederson et al. 2012; Seager et al. 2009).

Proxy reconstructions of drought allow studies of drought variability over much longer time scales than are available from the limited observational record. Improved sampling and characterization of multidecadal hydroclimate variability is therefore possible, including the occurrence of rare and extreme events such as pan-continental droughts. Additionally, paleo perspectives provide glimpses into different hydrological-mean states such as the often discussed megadroughts of the medieval era, periods of persistent (decadal and longer) drought that have few comparable analogs during the last 500 years (Cook et al. 2004, 2007, 2010; Gray et al. 2011; Herweijer et al. 2007; Meko et al. 2007; Routson et al. 2011; Stahle et al. 2007; Stine 1994; Woodhouse and Overpeck 1998; Woodhouse et al. 2010). Herein, we use a tree-ring-derived, spatially explicit, proxy reconstruction of North American hydroclimate variability to investigate the occurrence and forcing of pan-continental droughts over the last millennium. We focus our analyses on three principal research questions: 1) How often have pan-continental droughts occurred over the last 1000 years? 2) How variable is the occurrence of pancontinental droughts, and are certain spatial patterns more prevalent than others? 3) How strongly can the occurrence of these pan-continental droughts be linked to known teleconnections and modes of SST forcing?

\section{Methods and data}

\section{a. The North American Drought Atlas}

We use an updated version of the North American Drought Atlas (NADA; Cook et al. 1999, 2004), a treering reconstruction of the summer season [June-August (JJA)] Palmer drought severity index (PDSI; Palmer 1965). The PDSI is a locally normalized index of drought, reflecting the balance between moisture supply (precipitation) and demand (evapotranspiration as a function of temperature). Positive values of PDSI indicate wetterthan-normal conditions and negative values indicate drier-than-normal conditions. Because PDSI has a memory time scale of 12-18 months (Guttman 1998; VicenteSerrano et al. 2010), values during the summer season will reflect temperature and precipitation anomalies from throughout the year (e.g., St. George et al. 2010). The employed version of the NADA has improved areal coverage and spatial resolution $\left(0.5^{\circ}\right)$, allowing for more precise regional characterizations of drought variability. To achieve this, the tree-ring network used for reconstruction was increased by over 1000 tree-ring chronologies, many of which were from several hundred to over a thousand years long. In every case, the tree-ring chronologies were detrended using methods that explicitly preserved centennial-or-longer time scale variability due to climate. The success in doing this is evident in Cook et al. (2010), where two centennial-duration megadroughts in California, discovered by Stine (1994) using totally independent methods, were captured with great fidelity. The point-by-point method of PDSI 

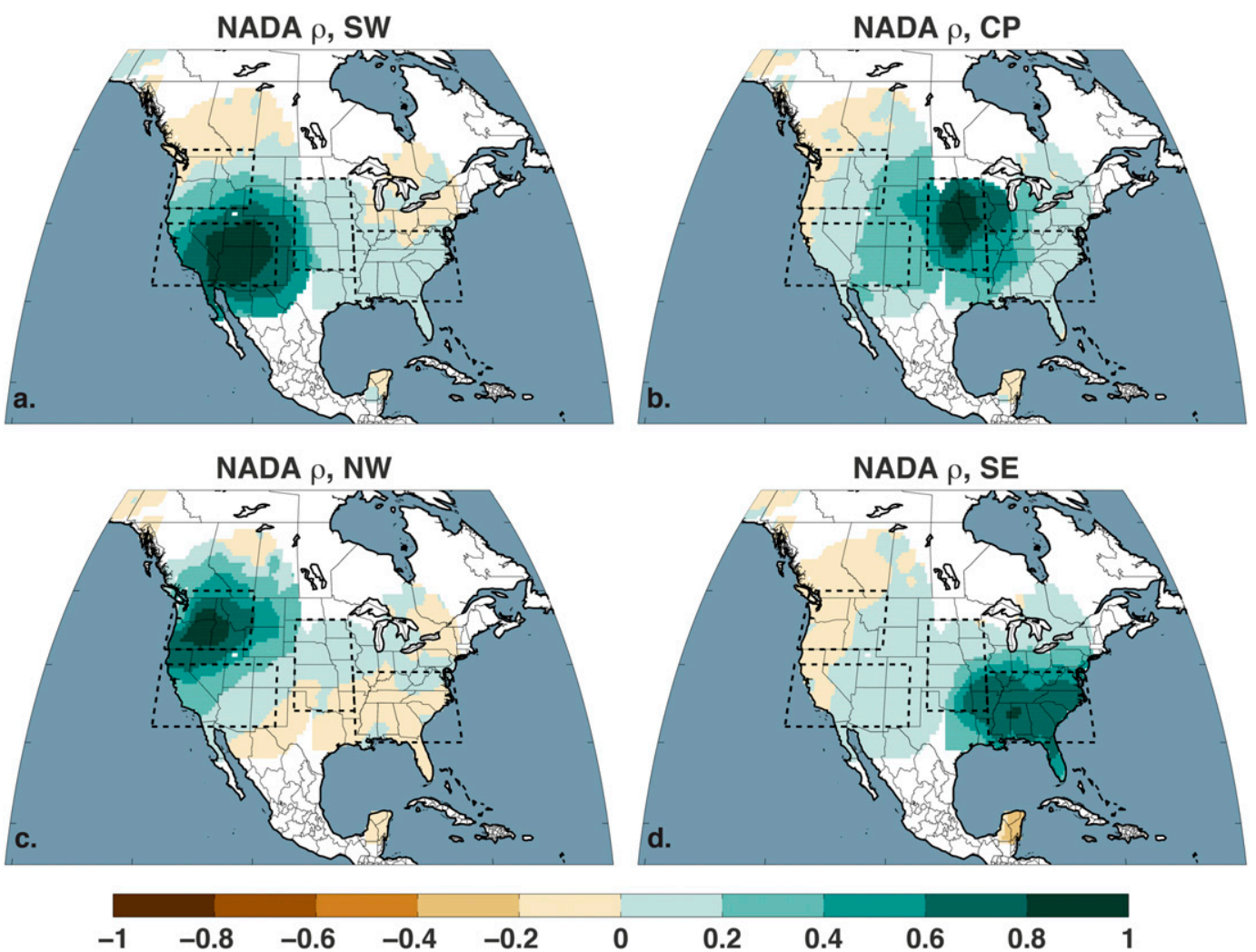

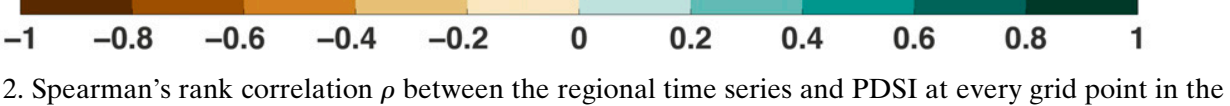
$0.5^{\circ}$-resolution NADA for 1000-2005 CE in the (a) SW, (b) CP, (c) NW, and (d) SE.

reconstruction, which uses a search radius of $450 \mathrm{~km}$, also guarantees that there is little overlap in the treering data used to reconstruct gridded drought in the four selected regions analyzed here (Fig. 2), thus making their comparisons with forcings at both high and low frequencies largely independent. While data from the NADA are available for the past 2000 years, we restrict our analyses to 1000-2005 Common Era (CE) to ensure consistent spatial and temporal coverage over our regions of interest. For the purposes of some temporal comparisons, we split the data into two eras: the Medieval Climate Anomaly (MCA; 1000$1500 \mathrm{CE}$ ) and the Little Ice Age/modern era (LIA/ MOD; 1501-2005 CE). The years bounding these two periods are loosely defined in the literature, and global analyses generally define the terminus of the MCA as some time during the thirteenth or fourteenth centuries (e.g., Graham et al. 2011; Mann et al. 2009). In North America, however, the megadroughts were the defining characteristic of medieval climate, and many of these events extended well into the fifteenth century. We therefore define the MCA in our analysis as 1000-1500 CE, and the LIA/MOD period as 1501-2005 CE.

\section{b. Climate indices}

To diagnose possible causes of pan-continental droughts in the NADA, we use three climate indices representative of the major SST modes linked to North American droughts. The Southern Oscillation index (SOI; Ropelewski and Jones 1987; Trenberth and Hoar 1996) is defined as the normalized difference in sea level pressure between the island of Tahiti and the city of Darwin in Australia, reflecting variations in the state of the El Niño-Southern Oscillation (ENSO) system. Positive values indicate La Niña conditions, typically associated with drought in the Southwest, southern plains, and the Southeast. We use the version provided by the Climate Prediction Center (CPC) of the National Weather Service, available monthly from 1882 to the present. As a test for how sensitive our results were to our choice of ENSO indicator (the SOI), we repeated all teleconnection analyses with the Niño-3.4 index, an SST-based indicator of ENSO variability. Analyses with the Niño-3.4 index yielded nearly identical results to our analyses based on the SOI. The Pacific decadal oscillation (PDO; Mantua et al. 1997; Mantua and Hare 2002) is defined as the leading principal component of monthly SST variability poleward of $20^{\circ} \mathrm{N}$ in 
the North Pacific Ocean. Positive phases of the PDO are generally linked to drought in the Northwest and wet conditions in the Southwest (McCabe et al. 2004, 2008). The degree to which the PDO is separable and distinct from ENSO is poorly understood, and there is some evidence that it may be simply a low-frequency, extratropical expression of ENSO (McCabe et al. 2008; Newman et al. 2003). While the physical mechanisms involved are therefore not fully elucidated, the impacts of the PDO on drought variability in North America are nevertheless well established (e.g., McCabe and Dettinger 2002; McCabe et al. 2004, 2008). We use the version provided by the Joint Institute for the Study of the Atmosphere and Ocean (University of Washington), available monthly from 1900 to the present. The Atlantic multidecadal oscillation (AMO) index is calculated as Atlantic SSTs averaged over $0^{\circ}-60^{\circ} \mathrm{N}, 0^{\circ}-80^{\circ} \mathrm{W}$ minus the global rise in SSTs averaged over $60^{\circ} \mathrm{S}-60^{\circ} \mathrm{N}$ so that it represents internal variability independent of any long-term greenhouse gas-forced trend (after Trenberth and Shea 2006). Positive values of the AMO, indicative of warm Atlantic SSTs, are typically associated with dry conditions in the central and southern plains and the Southeast (Kushnir et al. 2010; McCabe et al. 2004, 2008; Nigam et al. 2011). This version of the AMO index is calculated using the National Oceanic and Atmospheric Administration (NOAA) extended reconstructed SST dataset (version 3b), available monthly from 1854 to the present (Smith and Reynolds 2003).

\section{c. Analysis}

Within the conterminous United States, hydroclimatic variability is a recurrent, robust feature of the regional climate in four primary regions: the Southwest (Hoerling et al. 2009; Woodhouse et al. 2010), the Northwest (Nelson et al. 2011; Steinman et al. 2012), the central plains (Hoerling et al. 2009; Schubert et al. 2004a,b), and the Southeast (Pederson et al. 2012; Seager et al. 2009). For the subsequent analyses of pancontinental drought, we spatially average the NADA over these four regions to derive regional time series of PDSI (1000-2005 CE). Regional boundaries were chosen to maximize statistical independence between the PDSI time series, while still encompassing the major areas of drought variability: $\mathrm{SW}: 32^{\circ}-40^{\circ} \mathrm{N}, 125^{\circ}-105^{\circ} \mathrm{W}$; CP: $34^{\circ}-46^{\circ} \mathrm{N}, 102^{\circ}-92^{\circ} \mathrm{W}$; NW: $42^{\circ}-50^{\circ} \mathrm{N}, 125^{\circ}-110^{\circ} \mathrm{W}$; and SE: $30^{\circ}-39^{\circ} \mathrm{N}, 92^{\circ}-75^{\circ} \mathrm{W}$. We do not expect these four regions to be completely independent because of various processes that govern the spatial expression of drought, including topography, regional circulation, and various teleconnection modes. The correlation maps $(\rho)$ between these regional-average time series and PDSI at each grid point in the NADA (Fig. 2) nevertheless strongly indicate that positive correlations are concentrated within the bounding boxes of the defined regions (indicated by the black dashed boxes) and decay rapidly outside of them. These time series therefore can be interpreted as reasonably distinct and separable regions of drought variability, appropriate for our analysis. Droughts are characterized to have occurred in the regional-mean time series when PDSI falls to a value of -0.5 or lower in any individual year (a value of -0.5 being considered an incipient drought; see definition at http://www.esrl.noaa. gov/psd/data/usclimdivs/data/). We used a modest threshold of -0.5 rather than a more extreme value (e.g., -1.0$)$ to ensure adequate sampling of events over the last millennium and during the overlapping period with the teleconnection indices. A PDSI threshold of -0.5 , for example, yields $124 \mathrm{SW}, \mathrm{CP}$, and SE (hereafter, $\mathrm{SW}+\mathrm{CP}+\mathrm{SE}$ ) pan-continental drought events over the last 1000 years, while a threshold of -1.0 yields only 47 . During the instrumental period (1850-2005), a shift from -0.5 to -1.0 changes the number of events from 23 to 5 , drastically reducing our ability to sample the climate indices. With these considerations in mind, and given that NOAA refers to PDSI values of -0.5 as an incipient drought, we feel that a PDSI value of -0.5 is a statistically reasonable and physically defensible threshold. We define a pan-continental drought as any instance when any three $[\mathrm{SW}+\mathrm{CP}+\mathrm{SE} ; \mathrm{SW}, \mathrm{CP}$, and $\mathrm{NW}$ (hereafter, $\mathrm{SW}+\mathrm{CP}+\mathrm{NW}$ ); $\mathrm{SW}, \mathrm{NW}$, and $\mathrm{SE}$ (hereafter, $\mathrm{SW}+\mathrm{NW}+\mathrm{SE}$ ); or $\mathrm{CP}, \mathrm{NW}$, and $\mathrm{SE}$ (hereafter, $\mathrm{CP}+\mathrm{NW}+\mathrm{SE})]$ or all four [SW, $\mathrm{CP}, \mathrm{NW}$, and $\mathrm{SE}$ (hereafter, $\mathrm{SW}+\mathrm{CP}+\mathrm{NW}+\mathrm{SE}$ )] of our defined regions simultaneously have PDSI values of -0.5 or lower in the same year. By this definition, the four-region droughts will overlap with and also be counted as three-region droughts. While it would be possible to exclude the fourregion events from the three-region drought counts, we have chosen to allow this overlap to maximize the sampling of these relatively rare events. This sampling is especially important for the teleconnection analysis, which is limited to the observational period.

For both the single-region and pan-continental droughts, we analyze temporal changes in the drought occurrence and average aridity in the NADA, and use the observational climate indices (SOI, PDO, and AMO) to establish possible forcing mechanisms. We correlate $(\rho)$ the dynamic indices against each NADA grid point during their periods of overlap, focusing on the main seasons of influence associated with each climate mode: December-February (DJF) and March-May (MAM) for the SOI and PDO; and MAM and JJA for the AMO. Because the PDO and AMO represent low-frequency modes of variability (decadal and longer), the PDSI and 
climate indices are smoothed with a 10-yr locally weighted scatterplot smoothing (LOWESS) filter before conducting these correlations.

It is possible that pan-continental droughts do not arise primarily from large-scale forcing that organizes anomalies over large spatial scales (e.g., the AMO), but rather through the random superposition of drought events occurring independently in the four regions. To test this, we conduct a 5000-member ensemble resampling of each of the regional PDSI time series. In each ensemble member, we randomize the phase information of the regional PDSI time series [using the method of Ebisuzaki (1997)], generating new series in each region with identical lengths and power spectra, but different relative phasing of their spectral components. Any dependencies across regions are therefore removed and each new time series can be interpreted as an independent random draw from an underlying parent population defined by the autocorrelation structure of the original regional time series. We calculate the percentage occurrence of pan-continental droughts from these synthetic series, and then calculate the 95th percentile of occurrences across the entire ensemble. If the observed percent occurrence of pan-continental droughts in the NADA exceeds this 95th percentile threshold, we reject the null hypothesis that pan-continental droughts arise randomly from independent variability in each region.

To determine the significance of the drought teleconnections (SOI, PDO, and AMO), composite averages are computed for those climate index values associated with the single-region and pan-continental droughts. A 5000-member ensemble resampling of the climate indices is then performed to generate 90th and 95th percentile confidence limits. For example, during the full overlapping time period between the SOI data and the NADA (1882-2005), there are 41 years that qualify as SW droughts (Table 1). An average of the SOI values for these 41 years gives a composite SOI anomaly associated with these events. We then draw 41 random years from the SOI time series and average them, repeating this process 5000 times. If the original composited SOI anomaly exceeds the 90th or 95th percentile thresholds of the ensemble resampling, the drought-teleconnection association is characterized as marginally or fully significant, respectively.

\section{Results}

\section{a. Single-region drought comparisons}

The CP and SW are the prime epicenters for North American megadroughts, and long-term droughts during the MCA in these regions can be clearly seen in the
TABLE 1. The number of single-region and pan-continental drought years (PDSI $\leq-0.5)$ in the NADA available from the overlapping periods with the climate indices from the observational era. The climate indices are current up through 2012, but the NADA ends in 2005. Total overlap is 124 years for the SOI, 106 years for the PDO, and 152 years for the AMO.

\begin{tabular}{lrrr}
\hline \hline & SOI & PDO & AMO \\
\hline Single-region droughts & & & \\
SW & 41 & 36 & 57 \\
CP & 34 & 31 & 53 \\
NW & 41 & 36 & 52 \\
SE & 43 & 37 & 59 \\
Pan-continental droughts & & & \\
SW+CP+SE & 16 & 13 & 23 \\
SW+CP+NW & 8 & 7 & 12 \\
SW+NW+SE & 8 & 7 & 11 \\
CP+NW+SE & 12 & 11 & 17 \\
SW+CP+NW+SE & 7 & 6 & 9 \\
\hline
\end{tabular}

regional time series (Figs. 3a,b). Megadrought activity in the SW and CP peaks during the exceptionally dry twelfth, thirteenth, and fifteenth centuries. Notably, megadroughts across these two regions are not completely synchronous in time, and droughts in the CP have much longer persistence time scales than in the SW. This suggests that the megadroughts do not represent a single, unified phenomenon dominating western hydroclimate during the MCA. Rather, they behave as regionally distinct phenomena governed primarily by particular teleconnections and local land surface feedbacks, possibly with some longer time scale forcing making them more likely to occur during the MCA than during the more recent LIA/MOD period. Both regions transition to wetter mean conditions in more recent centuries.

Megadroughts are generally absent in the PDSI anomalies for the NW (Fig. 3c). Multidecadal pluvials are instead apparent during ca. 1090-1120, 1260-1350, and 1440-1475 CE. There is additionally little change in NW drought variability across the transition from the MCA to the LIA/MOD. In the SE (Fig. 3d), interannual drought variability is muted compared to the SW and $\mathrm{CP}$, and conditions are dry (in a regionally normalized sense) up to the middle of the nineteenth century, at which point a wetting trend to the present day begins. Independent corroboration of this long-term trend toward more pluvial conditions is difficult because few, if any, reconstructions of drought from this region are available that use completely independent proxy data from the NADA. However, this trend is apparent in more recent regional reconstructions that incorporate additional proxies independent of the NADA (Pederson et al. 2012, 2013), and the trend is consistent with independent studies of forest dynamics over the last several hundred years (McEwan et al. 2011). 

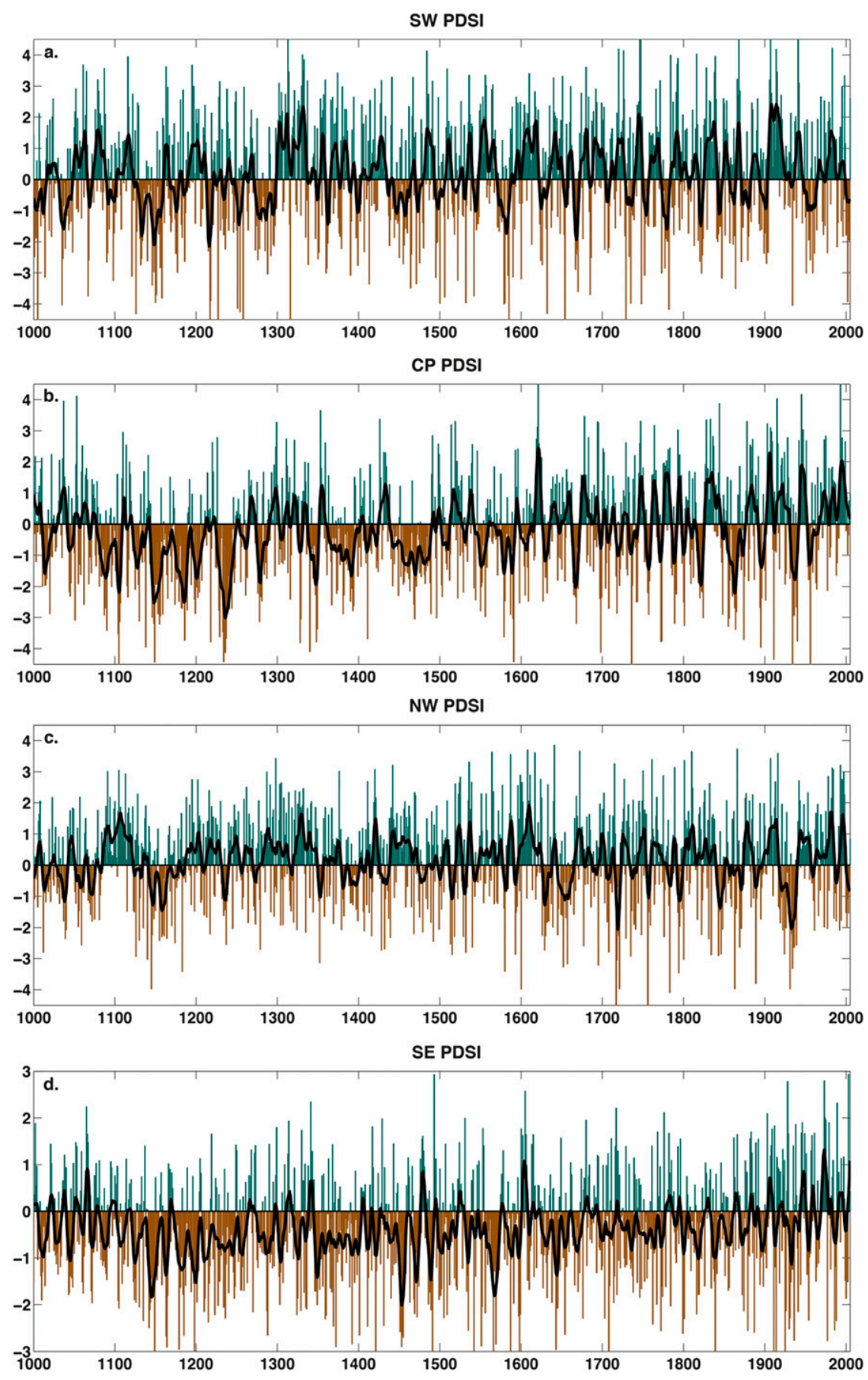

FIG. 3. Area-averaged PDSI from the NADA for the (a) SW, (b) CP, (c) NW, and (d) SE regions, as shown in Figs. 1 and 2. Green and brown bars are the original data, and dark black lines are a smoothed version of the time series using a 10-yr LOWESS spline.

Three of the regions (SW, CP, and SE) show longterm, multicentennial trends in drought frequency or occurrence (Fig. 4a), calculated from the eleventh to twentieth centuries. The number of droughts per century has declined significantly $(p \leq 0.01$, based on best-fit linear least squares regression) in the $\mathrm{CP}$ and $\mathrm{SE}$, on the order of -2.2 and -1.5 century $^{-1}$, respectively. There are also declines in the SW $\left(-1.0\right.$ century $\left.^{-1}\right)$, although this trend is not significant $(p=0.11)$. In step with the declines in drought frequency, mean PDSI has been 
No. Droughts (PDSI $\leq-0.5)$

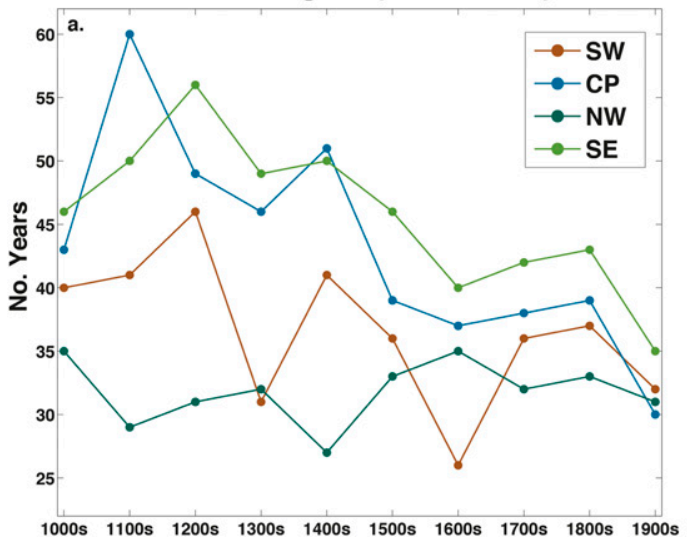

Mean PDSI

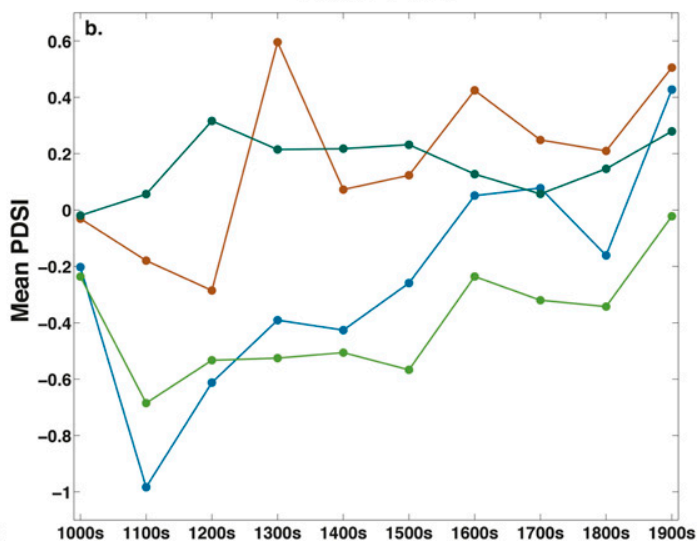

FIG. 4. Drought statistics derived from each of the regional time series: (a) number of drought years (PDSI $\leq-0.5)$ per century and (b) mean PDSI calculated across all years of each century.

increasing for the same three regions, indicating a trend toward wetter average conditions (Fig. 4b). The $\mathrm{CP}$ shows the strongest trend $\left(+0.10\right.$ century $^{-1}, p \leq$ $0.01)$, while trends in the SW $\left(+0.06\right.$ century $\left.^{-1}\right)$ and SE $\left(+0.04\right.$ century $\left.^{-1}\right)$ are weaker and only marginally significant $(p \leq 0.10)$. Trends in the NW are small and insignificant for both drought frequency and mean PDSI.

The extended periods of drought in the SW, CP, and SE during the MCA (Fig. 2) may indicate enhanced drought persistence, possibly due to sustained Atlantic or Pacific SST forcing (Burgman et al. 2010; Conroy et al. 2009; Feng et al. 2008; Oglesby et al. 2012; Seager et al. 2007a, 2008) or land surface feedbacks (Cook et al. 2013). We calculated the autocorrelation function (ACF) for each region separately for the MCA and LIA/MOD periods, after first adjusting each PDSI time series to a mean of zero (Fig. 5). Of all four regions during the MCA, the CP has the largest lag-1 persistence (Fig. 5b), twice as high as the SW, the other region of megadrought activity. Persistence during the MCA in the CP remains consistently high and generally significant out to 6 years, reflecting the extended, multidecadal periods of drought that defined climate in this region during the MCA (Fig. 2b). The SW has no significant autocorrelation between years 2 and 6 , but does have significant autocorrelation at lags of 7 and 8 years, possibly due to the strong decadal and cyclic drought variability in this region. Notably, the SE does not have any significant persistence during the MCA beyond 1 year. Drier conditions in the SE during the MCA therefore represent the beginning of a long-term wetting trend, rather than a fundamental change in the underlying variability. During the last 500 years, significant persistence beyond a lag of 1 year disappears for all regions, although droughts in the $\mathrm{CP}$ continue to have the highest lag-1 autocorrelation of any region.

\section{b. Incidence of pan-continental droughts}

The percent of total drought years for each of the five pan-continental drought configurations during 1000-2005 $\mathrm{CE}$ are indicated in the legend of Fig. 6. The single most common pan-continental drought pattern over the last thousand years is $\mathrm{SW}+\mathrm{CP}+\mathrm{SE}$, a pattern quite similar to the 2012 drought (see Fig. 1). The second most common pattern is $\mathrm{CP}+\mathrm{NW}+\mathrm{SE}$; followed by $\mathrm{SW}, \mathrm{CP}$, and $\mathrm{NW}$ (hereafter, $\mathrm{SW}+\mathrm{CP}+\mathrm{NW}$ ); and $\mathrm{SW}+\mathrm{NW}+\mathrm{SE}$. The incidence of drought in all four regions simultaneously is only $5.2 \%$ of years. There is substantial centennial-scale variability in the occurrence of these droughts (Fig. 6), especially for the $\mathrm{SW}+\mathrm{CP}+\mathrm{SE}$ droughts that are particularly prevalent during the exceptionally dry twelfth and thirteenth centuries. Only the $\mathrm{SW}+\mathrm{CP}+\mathrm{NW}$ combination shows a small and marginally significant $(p \leq 0.10)$ trend toward decreased occurrence $\left(-0.47\right.$ century $\left.^{-1}\right)$ over the course of the millennium. For all the pancontinental events, the observed percentages of occurrence exceed the 99th percentile from our phase-randomized resampling. This strongly suggests that pan-continental droughts are unlikely to occur as a random consequence of independent regional variability, instead indicating that they are likely triggered by coherent forcing or dynamics acting across regions.

Average recurrence intervals for single-region (Fig. 7a) and pan-continental (Fig. 7b) droughts increase with the transition from the MCA to LIA/MOD period, consistent with other indicators indicating a shift toward wetter conditions in North America. For single-region droughts, recurrence intervals range from roughly 2 to 3 years; for pan-continental droughts, the recurrence intervals are all 10 years or more, except for the most common pattern, $\mathrm{SW}+\mathrm{CP}+\mathrm{SE}$, which recurs on average every 7 or 9 years during the MCA and LIA/MOD 


\section{Regional ACFs}

SW
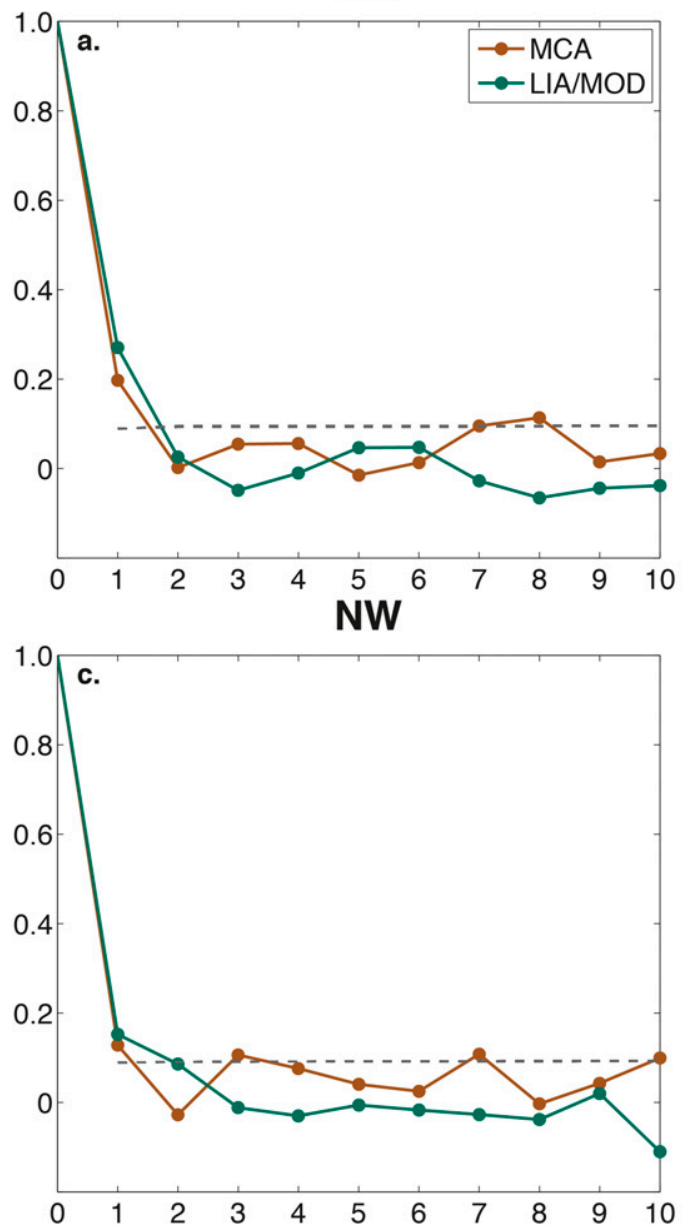

CP
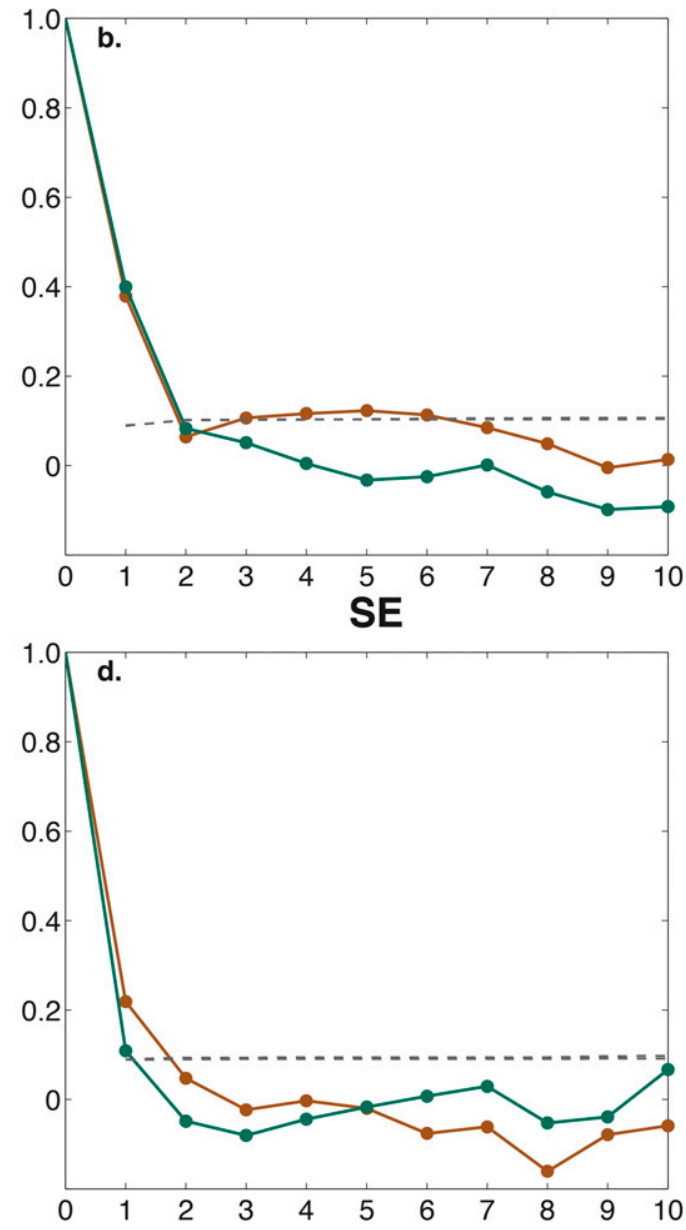

FIG. 5. ACF for each regional PDSI time series for the MCA (brown solid lines; 1000-1500 CE) and LIA/MOD (green solid lines; 1501-2005 CE) periods: (a) SW, (b) CP, (c) NW, and (d) SE. Significance thresholds (dashed lines) are based on twice the large-lag standard error of the ACF. Prior to calculating the ACFs, time series were adjusted to a mean of zero to remove the influence of shifts in the average baseline.

periods, respectively. Four-region $(\mathrm{SW}+\mathrm{CP}+\mathrm{NW}+\mathrm{SE})$ droughts are especially rare, occurring on average 1 $(20 \mathrm{yr})^{-1}$ over the last 500 years.

\section{c. Forcing of pan-continental droughts}

Spearman rank correlations between the NADA and the climate indices (SOI, PDO, and AMO) offer strong evidence for the potentially important role of these climate modes in forcing regional and pan-continental droughts (Fig. 8). Positive values of the SOI have a strong association with drought in the SW and southern parts of the CP; the influence of the SOI weakens with the transition from winter (Fig. 8a) to spring (Fig. 8b). Positive values of the PDO in winter and spring correlate strongly with drought in the NW and SE and pluvial conditions in the SW (Figs. 8c,d). The PDO correlation pattern has some similarity to the SOI correlation, which is not surprising given that the PDO is negatively correlated with the SOI (Newman et al. 2003). It is worth noting, however, that the major centers of strong correlation differ between the two correlation modes. Specifically, the PDO over western North America includes a NW-SW dipole that the SOI correlation lacks. Correlations with the AMO (Figs. 8e,f) are generally negative and widespread, with strongest loadings in the SW, CP, and SE (Figs. $8 \mathrm{e}, \mathrm{f})$, indicating the tendency for a positive AMO (i.e., warm Atlantic SSTs) to favor widespread drought (Kushnir et al. 2010; McCabe et al. 2004; Nigam et al. 2011). 


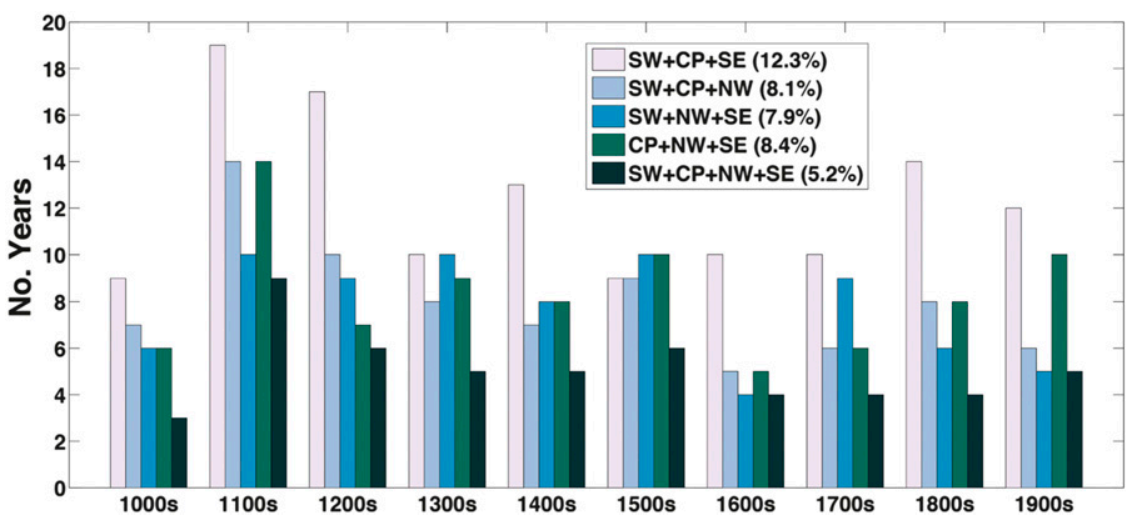

FIG. 6. Number of pan-continental drought years (PDSI $\leq-0.5)$ in each century, calculated for all possible pan-continental drought patterns. To ensure adequate sampling of events, drought years were allowed to overlap between the three- and four-region drought categories. The total percent occurrences of each drought pattern, calculated over the full time period available (1000-2005 CE), are indicated in the figure legend.

The ACFs of the climate indices (Fig. 9) offer some clues regarding differences in drought variability (Fig. 3) and drought persistence (Fig. 5) between the SW and $\mathrm{CP}$ regions. Autocorrelation in the SOI, which loads strongly over the SW (Fig. 8a), varies between significantly negative (lags at 2 and 7 years) and significantly positive (5 years) values, which is an autocorrelation structure typical of oscillatory phenomena. In other words, any SOI-forced drought in the SW is likely to be followed by an opposite-sign SOI event within 2 years, bringing relatively wet conditions that oppose the initial drought, limiting drought persistence. In contrast, the AMO has significant persistence that slowly decays out to 5 years, with little evidence for any strongly oscillatory behavior. Given the apparent importance of the
AMO for drought in the CP (Figs. 8e,f), this suggests that this SST pattern may contribute to the exceptional persistence of droughts over the CP (persistence in the $\mathrm{CP}$ is higher than any of the other three regions, especially during the MCA).

For the single-region drought composites, from 30 to almost 60 drought-event years are available during the overlapping time period between the NADA and the climate indices (Table 1). Composite climate index values for single-region droughts are shown in Fig. 10; composites passing the 90th and 95th percentile estimated confidence limits are marked with single and double asterisks, respectively. Composited SOI values are significant and positive for the SW, showing a stronger winter signal consistent with the correlation map of Fig. 8.

\section{Drought Recurrence Intervals}
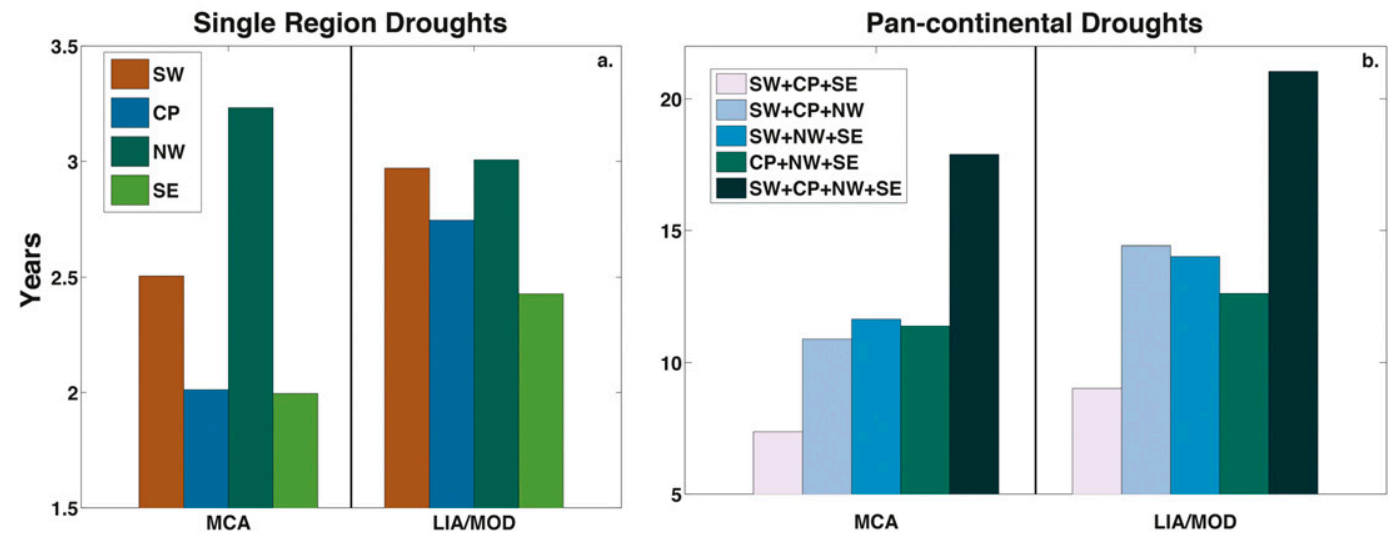

FIG. 7. Drought recurrence intervals for (a) single-region and (b) pan-continental droughts, calculated separately for the MCA and LIA/MOD intervals. Note that the ranges of the $y$ axes are different in (a) and (b) because of the much larger recurrence intervals associated with the pan-continental droughts. 


\section{Teleconnections $(\rho)$}
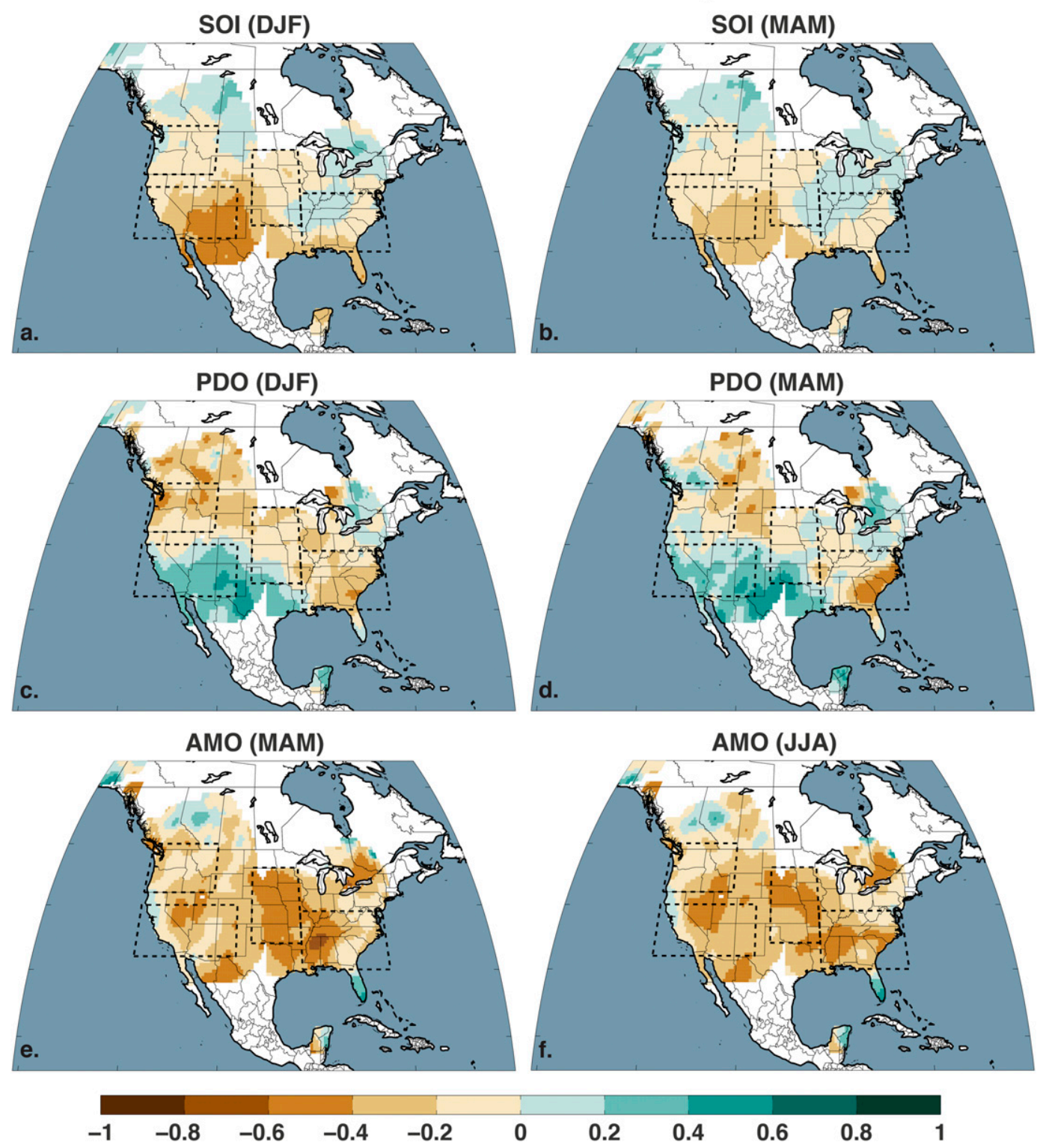

FIG. 8. Correlations between gridpoint PDSI from the NADA and: SOI in (a) DJF and (b) MAM, PDO in (c) DJF and (d) MAM, and AMO in (e) MAM and (f) JJA. For the PDO and AMO, correlations are based on filtered (10-yr LOWESS) PDSI and climate indices.

PDO composites are positive and significant for droughts in the CP, NW, and the SE during DJF. The MAM PDO signal is not significant, and this may be due to the large number of drought years in the SE during the nineteenth century, reflecting the long-term wetting trend that is unlikely to be related to any changes in the PDO. The AMO composites show significant positive index values for the $\mathrm{CP}$ and SE in both the spring and summer, but no significant association with SW droughts, despite the strong negative correlation in Fig. 8 and previous research identifying a strong AMO-drought link in this region (McCabe et al. 2004, 2008).

Fewer composite years are available for pan-continental droughts (Table 1), reflecting their relative scarcity, especially during the instrumental period. Three drought patterns appear to have significant climate index composites (Fig. 11): $\mathrm{SW}+\mathrm{CP}+\mathrm{SE}(+\mathrm{SOI}$ in DJF), $\mathrm{SW}+\mathrm{CP}+\mathrm{NW}$ $(+\mathrm{SOI}$ in $\mathrm{DJF}$ and $+\mathrm{PDO}$ in DJF), and $\mathrm{CP}+\mathrm{NW}+\mathrm{SE}$ (+PDO in DJF; +PDO in MAM; + AMO in MAM, and + AMO in JJA). Interestingly, these are the most 


\section{ACFs, Climate Indices}
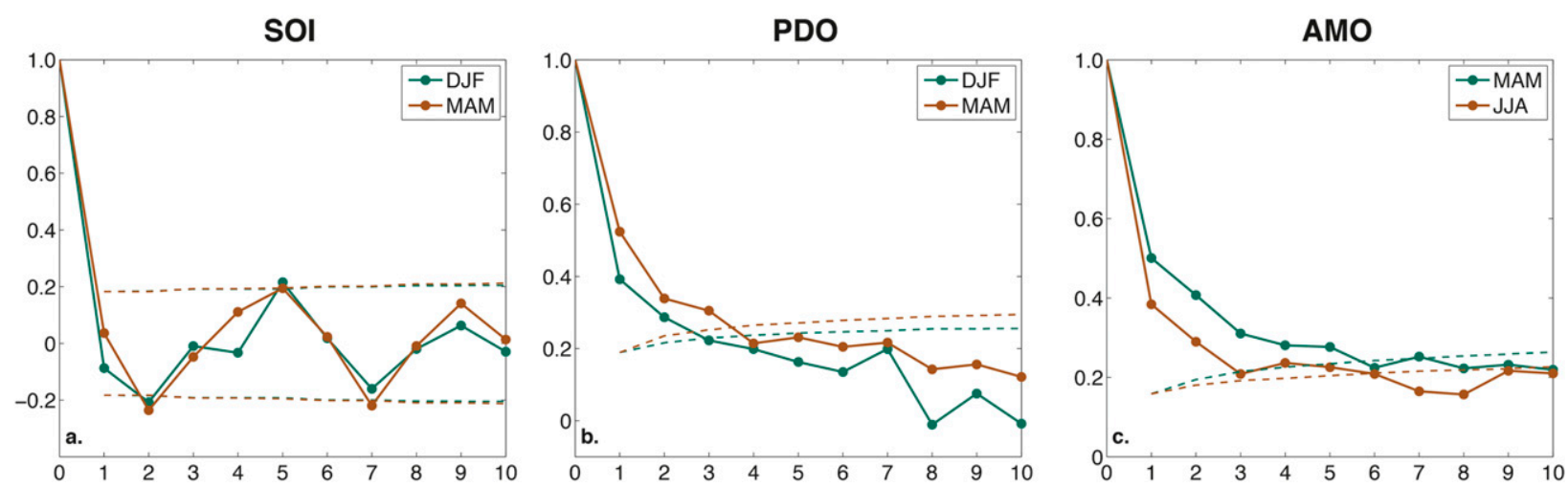

FIG. 9. ACF for: (a) SOI (1884-2012), (b) PDO (1900-2012), and (c) AMO (1854-2012). Significance thresholds (dashed lines) are based on 2 times the large-lag standard error of the autocorrelation function. Brown lines are the function based on the MAM (SOI and PDO) and JJA (AMO) seasonal-average time series; green lines are for DJF (SOI and PDO) and MAM (AMO). Prior to calculating the ACFs, time series were adjusted to a mean of zero to remove the influence of shifts in the average baseline.

common pan-continental drought patterns to occur in the last thousand years. This suggests that there may be some predictability for these types of pan-continental droughts at leads of one season or more, given that the current states of the AMO and PDO can be estimated and the SOI can be predicted a few seasons in advance. These teleconnection patterns could also explain the enhanced occurrence of these droughts during the MCA (e.g., the 1100s; Fig. 6), consistent with previous work suggesting possible SST forcing of megadrought activity (Burgman et al. 2010; Feng et al. 2008; Graham et al. 2011; Seager et al. 2007a, 2008; Oglesby et al. 2012).

\section{Discussion and conclusions}

Droughts are one of the most expensive natural disasters to affect the United States, causing significant harm to agriculture, human health, and the economy at large (Ross and Lott 2003). The 2011 drought, a regional event centered in the Southwest and southern plains, cost $\$ 12$ billion and contributed to 95 deaths (NCDC 2013c). The impact of the 2012 drought, a pan-continental event, was much more severe. During 2012, $80 \%$ of the agricultural land in the United States experienced drought conditions, the largest area in a single year since the 1950s (USDA 2013), and corn yields were $26 \%$ below expectations (Hoerling et al. 2013). The drought also contributed toward making 2012 the third all-time highest record year for area burned (NCDC 2013b). Ultimately, the 2012 drought was the second most expensive natural disaster of 2012 (after Hurricane Sandy), causing $\$ 30$ billion dollars in damages and 123 deaths (NCDC 2013c), underlining the significant stresses and management challenges imposed by these pan-continental events.

Much effort has been devoted to understanding the causes of regional droughts in the past (e.g., Coats et al. 2013b; Cook et al. 2009; Ellis et al. 2010; Herweijer et al.

\section{Teleconnection Composites (Single-Region Droughts)}
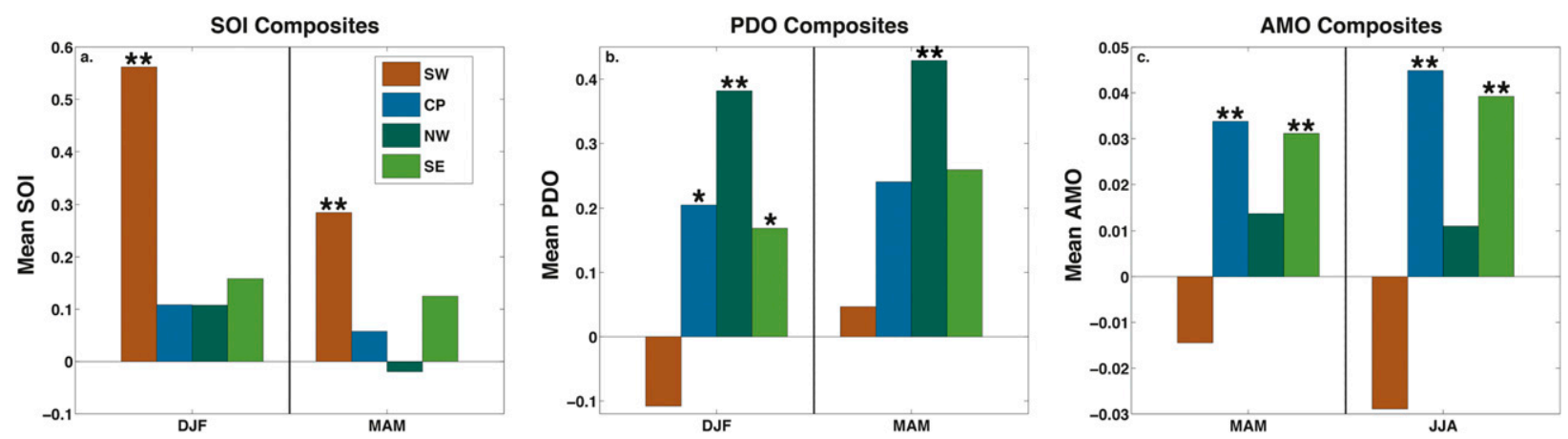

FIG. 10. Composite averages of climate indices during drought years (PDSI $\leq-0.5$ ) for each region: (a) SOI, (b) PDO, and (c) AMO.

Significant composites, based on the resampling described in section 2, are indicated by single (90th) and double (95th) asterisks. 


\section{Teleconnection Composites (Pan-Continental Droughts)}
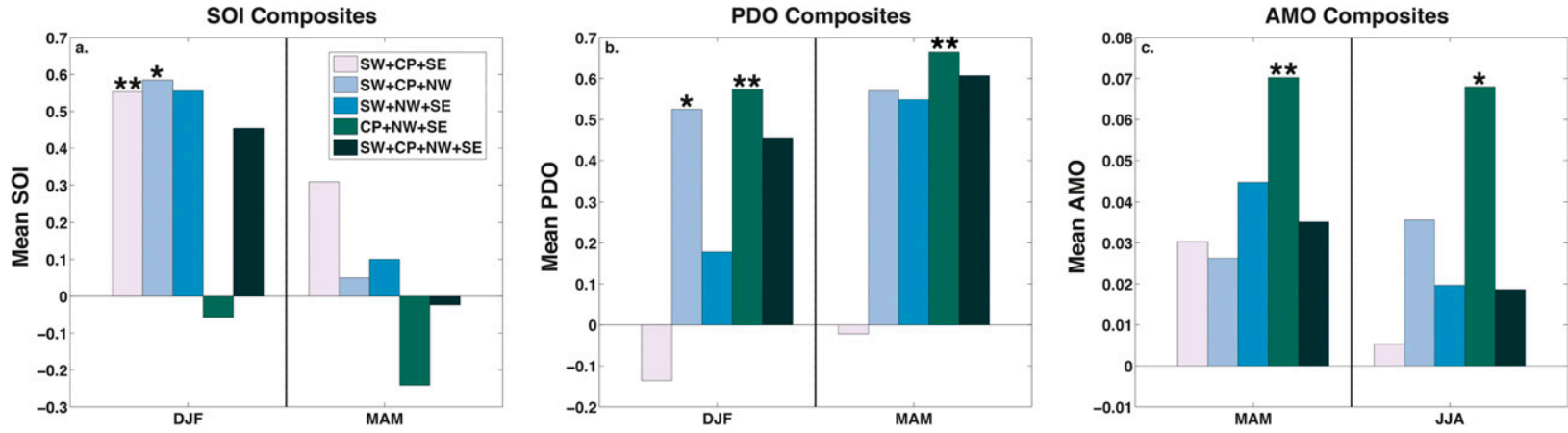

FIG. 11. As in Fig. 10, but for the pan-continental drought patterns.

2006; Hoerling et al. 2009; Schubert et al. 2004b) and how they may change with increased greenhouse gas forcing in the future (Seager et al. 2007b; Seager and Vecchi 2010; Seager et al. 2013). Few studies, however, have focused on the occurrence and variability of multiregional, pan-continental droughts. We find that pancontinental droughts have occurred in various flavors over the last millennium, and that the 2012 drought is similar to the most common type of pan-continental drought pattern found in the paleo record $(\mathrm{SW}+\mathrm{CP}+\mathrm{SE})$. We also find that the occurrences of certain pan-continental drought patterns $(\mathrm{SW}+\mathrm{CP}+\mathrm{SE}, \mathrm{SW}+\mathrm{CP}+\mathrm{NW}$, and $\mathrm{CP}+\mathrm{NW}+\mathrm{SE}$ ) are strongly linked to well-known teleconnections originating from the Pacific and Atlantic Oceans. Teleconnections are therefore capable of influencing the probability of occurrence of pan-continental droughts, although any particular event could also be influenced by internal atmospheric variability unrelated to ocean conditions. For example, Hoerling et al. (2013) concluded that the 2012 drought was made more likely by slowly varying SSTs, but that the particulars of the summer 2012 drought in the Plains was strongly controlled by seemingly random circulation anomalies. Interestingly, our analyses of the CP and SW also found that the MCA megadroughts were generally not synchronous in time across these two regions and also exhibited significantly different persistence characteristics. This result is not necessarily surprising, given the very different climatologies and drought teleconnections associated with each region. Our analysis does indicate, however, that the megadroughts in North America should not be viewed as a single, coherent phenomenon affecting the entire western United States, but rather as a superposition of potentially separable regional events.

Understanding the underlying dynamics and predictability of pan-continental droughts remains a significant challenge. Interpretations from our teleconnection analysis are limited by the relative paucity of pan-continental droughts available from the observational era. For example, only six $\mathrm{SW}+\mathrm{CP}+\mathrm{NW}+\mathrm{SE}$ droughts overlap with the PDO record (Table 1), making it difficult to determine whether the full range of climate conditions and teleconnections associated with these droughts is being fully captured. This limitation could be potentially addressed through the use of proxy reconstructions of these major teleconnection modes (e.g., Cobb et al. 2003, 2013; D'Arrigo et al. 2001; Emile-Geay et al. 2013a,b; Gray et al. 2004; Li et al. 2011), allowing for greater temporal overlap with the NADA. It is difficult, however, to find reconstructions that are continuous in time, precisely dated enough to allow for comparison with the NADA, and (most critically) based on completely independent proxy records. As an alternative, general circulation model simulations, such as those organized under phase 5 of the Coupled Model Intercomparison Project (CMIP5; Taylor et al. 2012), may provide another opportunity to investigate the dynamics and teleconnections driving pan-continental droughts. Nevertheless, the efficacy of these models to address the pan-continental drought problem depends crucially on their ability to skillfully reproduce the proper teleconnections, feedbacks, and time scales of response (e.g., Coats et al. 2013a).

Given the ubiquity of pan-continental droughts over the last millennium, it is likely that they will be an important and significant feature of North American hydroclimate in the decades and centuries to come, with potential changes in their severity and/or occurrence with increased greenhouse gas forcing. southwestern North America and the plains, for example, are expected to continue drying into the future (Seager et al. 2007b, 2013), with greenhouse warming causing both precipitation declines and increased evaporative demand in these regions. From a pan-continental perspective, warmer temperatures may be especially important, as temperature responses to increased greenhouse gases are likely 
to be more widespread and homogenous than precipitation changes (e.g., Knutti and Sedlacek 2013). This spatially extensive warming, and the accompanying increase in evaporative demand, represents a broad forcing that may increase the spatial coherence of droughts across regions, increasing the likelihood that multiple regions will experience drought simultaneously and amplifying the impacts on ecosystems, agriculture, and society at large, as was seen in 2012. Nevertheless, a complete quantification of the impacts of greenhouse warming on pan-continental droughts will require the analysis of climate model simulations that can accurately reproduce the underlying dynamics governing drought variability over North America.

Acknowledgments. The authors acknowledge support from NOAA award "Global Decadal Hydroclimate Variability and Change" (NA10OAR431037), and from NSF Grants ATMO9-02716 and ATM-06-20066. BI Cook also acknowledges the support of National Aeronautics and Space Administration Atmospheric Composition Program. The authors thank three anonymous reviewers for helpful comments that greatly improved the quality of this manuscript.

\section{REFERENCES}

Burgman, R., R. Seager, A. Clement, and C. Herweijer, 2010: Role of tropical Pacific SSTs in global medieval hydroclimate: A modeling study. Geophys. Res. Lett., 37, L06705, doi:10.1029/ 2009GL042239.

Coats, S., J. E. Smerdon, B. I. Cook, and R. Seager, 2013a: Stationarity of the tropical Pacific teleconnection to North America in CMIP5/PMIP3 model simulations. Geophys. Res. Lett., doi:10.1002/grl.50938, in press.

,,-- R. Seager, B. I. Cook, and J. F. González-Rouco, 2013b: Megadroughts in southwestern North America in millenniumlength ECHO-G simulations and their comparison to proxy drought reconstructions. J. Climate, 26, 7635-7649.

Cobb, K. M., C. D. Charles, H. Cheng, and R. L. Edwards, 2003: El Niño/Southern Oscillation and tropical Pacific climate during the last millennium. Nature, 424, 271-276, doi:10.1038/ nature 01779 .

_ N. Westphal, H. R. Sayani, J. T. Watson, E. Di Lorenzo, H. Cheng, R. L. Edwards, and C. D. Charles, 2013: Highly variable El Niño-Southern Oscillation throughout the Holocene. Science, 339, 67-70, doi:10.1126/science.1228246.

Conroy, J. L., J. T. Overpeck, J. E. Cole, and M. Steinitz-Kannan, 2009: Variable oceanic influences on western North American drought over the last 1200 years. Geophys. Res. Lett., 36, L17703, doi:10.1029/2009GL039558.

Cook, B. I., R. L. Miller, and R. Seager, 2009: Amplification of the North American "Dust Bowl" drought through humaninduced land degradation. Proc. Natl. Acad. Sci. USA, 106, 4997-5001, doi:10.1073/pnas.0810200106.

_ R. Seager, R. L. Miller, and J. A. Mason, 2013: Intensification of North American megadroughts through surface and dust aerosol forcing. J. Climate, 26, 4414-4430.
Cook, E. R., D. M. Meko, D. W. Stahle, and M. K. Cleaveland, 1999: Drought reconstructions for the continental United States. J. Climate, 12, 1145-1162.

- C. A. Woodhouse, C. M. Eakin, D. M. Meko, and D. W. Stahle, 2004: Long-term aridity changes in the western United States. Science, 306, 1015-1018, doi:10.1126/science.1102586.

—, R. Seager, M. A. Cane, and D. W. Stahle, 2007: North American drought: Reconstructions, causes, and consequences. Earth Sci. Rev., 81, 93-134, doi:10.1016/j.earscirev.2006.12.002.

,,-- R. R. Heim Jr., R. S. Vose, C. Herweijer, and C. Woodhouse, 2010: Megadroughts in North America: Placing IPCC projections of hydroclimatic change in a long-term palaeoclimate context. J. Quat. Sci., 25, 48-61, doi:10.1002/ jqs.1303.

D'Arrigo, R., R. Villalba, and G. Wiles, 2001: Tree-ring estimates of Pacific decadal climate variability. Climate Dyn., 18, 219224, doi:10.1007/s003820100177.

Ebisuzaki, W., 1997: A method to estimate the statistical significance of a correlation when the data are serially correlated. J. Climate, 10, 2147-2153.

Ellis, A. W., G. B. Goodrich, and G. M. Garfin, 2010: A hydroclimatic index for examining patterns of drought in the Colorado River basin. Int. J. Climatol., 30, 236-255, doi:10.1002/joc.1882.

Emile-Geay, J., K. M. Cobb, M. E. Mann, and A. T. Wittenberg, 2013a: Estimating central equatorial Pacific SST variability over the past millennium. Part I: Methodology and validation. J. Climate, 26, 2302-2328.

$\ldots, \ldots, \ldots$, and $\_$2013b: Estimating central equatorial Pacific SST variability over the past millennium. Part II: Reconstructions and Implications. J. Climate, 26, 2329-2352.

Fan, Y., and H. van den Dool, 2004: Climate Prediction Center global monthly soil moisture data set at $0.5^{\circ}$ resolution for 1948 to present. J. Geophys. Res., 109, D10102, doi:10.1029/ 2003JD004345.

Feng, S., R. J. Oglesby, C. M. Rowe, D. B. Loope, and Q. Hu, 2008: Atlantic and Pacific SST influences on medieval drought in North America simulated by the Community Atmospheric Model. J. Geophys. Res., 113, D11101, doi:10.1029/2007JD009347.

Graham, N. E., C. M. Ammann, D. Fleitmann, K. M. Cobb, and J. Luterbacher, 2011: Support for global climate reorganization during the "Medieval Climate Anomaly." Climate Dyn., 37, 1217-1245, doi:10.1007/s00382-010-0914-z.

Gray, S. T., L. J. Graumlich, J. L. Betancourt, and G. T. Pederson, 2004: A tree-ring based reconstruction of the Atlantic multidecadal oscillation since 1567 A.D. Geophys. Res. Lett., 31, L12205, doi:10.1029/2004GL019932.

_ J. J. Lukas, and C. A. Woodhouse, 2011: Millennial-length records of streamflow from three major upper Colorado River tributaries. J. Amer. Water Resour. Assoc., 47, 702712, doi:10.1111/j.1752-1688.2011.00535.x.

Guttman, N. B., 1998: Comparing the Palmer drought index and the standardized precipitation index. J. Amer. Water Resour. Assoc., 34, 113-121, doi:10.1111/j.1752-1688.1998.tb05964.x.

Herweijer, C., R. Seager, and E. R. Cook, 2006: North American droughts of the mid to late nineteenth century: A history, simulation and implication for mediaeval drought. Holocene, 16, 159-171, doi:10.1191/0959683606hl917rp.

- — _ - and J. Emile-Geay, 2007: North American droughts of the last millennium from a gridded network of tree-ring data. J. Climate, 20, 1353-1376.

Hoerling, M., X. W. Quan, and J. Eischeid, 2009: Distinct causes for two principal U.S. droughts of the 20th century. Geophys. Res. Lett., 36, L19708, doi:10.1029/2009GL039860. 
—, J. Eischeid, A. Kumar, R. Leung, A. Mariotti, K. Mo, S. Schubert, and R. Seager, 2013: Causes and predictability of the 2012 Great Plains drought. Bull. Amer. Meteor. Soc., in press.

Knutti, R., and J. Sedlacek, 2013: Robustness and uncertainties in the new CMIP5 climate model projections. Nat. Climate Change, 3, 369-373, doi:10.1038/nclimate1716.

Kushnir, Y., R. Seager, M. Ting, N. Naik, and J. Nakamura, 2010: Mechanisms of tropical Atlantic SST influence on North American precipitation variability. J. Climate, 23, 5610-5628.

Li, J., S.-P. Xie, E. R. Cook, G. Huang, R. D'Arrigo, F. Liu, J. Ma, and X.-T. Zheng, 2011: Interdecadal modulation of El Niño amplitude during the past millennium. Nat. Climate Change, $\mathbf{1}$, 114-118, doi:10.1038/nclimate1086.

Mann, M. E., and Coauthors, 2009: Global signatures and dynamical origins of the Little Ice Age and Medieval Climate Anomaly. Science, 326, 1256-1260, doi:10.1126/science.1177303.

Mantua, N. J., and S. R. Hare, 2002: The Pacific decadal oscillation. J. Oceanogr., 58, 35-44, doi:10.1023/A:1015820616384.

— — _ Y. Yhang, J. M. Wallace, and R. C. Francis, 1997: A Pacific interdecadal climate oscillation with impacts on salmon production. Bull. Amer. Meteor. Soc., 78, 1069-1079.

McCabe, G. J., and M. D. Dettinger, 2002: Primary modes and predictability of year-to-year snowpack variations in the western United States from teleconnections with Pacific Ocean climate. J. Hydrometeor., 3, 13-25.

- M. A. Palecki, and J. L. Betancourt, 2004: Pacific and Atlantic Ocean influences on multidecadal drought frequency in the United States. Proc. Natl. Acad. Sci. USA, 101, 4136-4141, doi:10.1073/pnas.0306738101.

—_, J. L. Betancourt, S. T. Gray, M. A. Palecki, and H. G. Hidalgo, 2008: Associations of multi-decadal sea-surface temperature variability with US drought. Quat. Int., 188, 31-40, doi:10.1016/j.quaint.2007.07.001.

McEwan, R. W., J. M. Dyer, and N. Pederson, 2011: Multiple interacting ecosystem drivers: Toward an encompassing hypothesis of oak forest dynamics across eastern North America. Ecography, 34, 244-256, doi:10.1111/j.1600-0587.2010.06390.x.

Meko, D. M., C. A. Woodhouse, C. A. Baisan, T. Knight, J. J. Lukas, M. K. Hughes, and M. W. Salzer, 2007: Medieval drought in the upper Colorado River basin. Geophys. Res. Lett., 34, L10705, doi:10.1029/2007GL029988.

Mo, K. C., and J. E. Schemm, 2008: Relationships between ENSO and drought over the southeastern United States. Geophys. Res. Lett., 35, L15701, doi:10.1029/2008GL034656.

NCDC, cited 2013a: State of the climate: Drought-annual 2012. National Oceanic and Atmospheric Administration. [Available online at http://www.ncdc.noaa.gov/sotc/drought/.]

_ cited 2013b: State of the climate, wildfires annual 2012. National Oceanic and Atmospheric Administration. [Available online at http://www.ncdc.noaa.gov/sotc/fire/2012/13.]

, 2013c: Billion dollar U.S. weather/climate disasters 1980-2012. National Climatic Data Center Tech. Rep., 6 pp. [Available online at http://www.ncdc.noaa.gov/billions/events.pdf.]

Nelson, D. B., and Coauthors, 2011: Drought variability in the Pacific Northwest from a 6,000-yr lake sediment record. Proc. Natl. Acad. Sci. USA, 108, 3870-3875, doi:10.1073/pnas.1009194108.

Newman, M., G. P. Compo, and M. A. Alexander, 2003: ENSOforced variability of the Pacific decadal oscillation. J. Climate, 16, 3853-3857.

Nigam, S., B. Guan, and A. Ruiz-Barradas, 2011: Key role of the Atlantic multidecadal oscillation in 20th century drought and wet periods over the Great Plains. Geophys. Res. Lett., 38, L16713, doi:10.1029/2011GL048650.
Oglesby, R., S. Feng, Q. Hu, and C. Rowe, 2012: The role of the Atlantic multidecadal oscillation on medieval drought in North America: Synthesizing results from proxy data and climate models. Global Planet. Change, 84-85, 56-65, doi:10.1016/ j.gloplacha.2011.07.005.

Palmer, W. C., 1965: Meteorological drought. U.S. Weather Bureau Research Paper 45, 58 pp.

Pederson, N., and Coauthors, 2012: A long-term perspective on a modern drought in the American Southeast. Environ. Res. Lett., 7, 014034, doi:10.1088/1748-9326/7/1/014034.

_ A. R. Bell, E. R. Cook, U. Lall, N. Devineni, R. Seager, K. Eggleston, and K. P. Vranes, 2013: Is an epic pluvial masking the water insecurity of the greater New York City region? J. Climate, 26, 1339-1354.

Ropelewski, C. F., and P. D. Jones, 1987: An extension of the Tahiti-Darwin Southern Oscillation index. Mon. Wea. Rev., 115, 2161-2165.

Ross, T. F., and N. Lott, 2003: A climatology of 1980-2003 extreme weather and climate events. National Climatic Data Center Tech. Rep., 28 pp.

Routson, C. C., C. A. Woodhouse, and J. T. Overpeck, 2011: Second century megadrought in the Rio Grande headwaters, Colorado: How unusual was medieval drought? Geophys. Res. Lett., 38, L22703, doi:10.1029/2011GL050015.

Schubert, S. D., M. J. Suarez, P. J. Pegion, R. D. Koster, and J. T. Bacmeister, 2004a: Causes of long-term drought in the U.S. Great Plains. J. Climate, 17, 485-503.

$-, \ldots,-,-\frac{1}{-}$, and,$- 2004 \mathrm{~b}$ : On the cause of the $1930 \mathrm{~s}$ Dust Bowl. Science, 303, 1855-1859, doi:10.1126/science.1095048. - and Coauthors, 2009: A U.S. CLIVAR project to assess and compare the responses of global climate models to droughtrelated SST forcing patterns: Overview and results. J. Climate, 22, 5251-5272.

Seager, R., and G. A. Vecchi, 2010: Greenhouse warming and the 21st century hydroclimate of southwestern North America. Proc. Natl. Acad. Sci. USA, 107, 21277-21282, doi:10.1073/ pnas.0910856107.

— Y. Y. Kushnir, C. Herweijer, N. Naik, and J. Velez, 2005: Modeling of tropical forcing of persistent droughts and pluvials over western North America: 1856-2000. J. Climate, 18, 4065-4088.

— N. Nraham, C. Herweijer, A. L. Gordon, Y. Kushnir, and E. Cook, 2007a: Blueprints for medieval hydroclimate. Quat. Sci. Rev., 26, 2322-2336, doi:10.1016/j.quascirev.2007.04.020.

_ , and Coauthors, 2007b: Model projections of an imminent transition to a more arid climate in southwestern North America. Science, 316, 1181-1184, doi:10.1126/science.1139601.

— , R. Burgman, Y. Kushnir, A. Clement, E. Cook, N. Naik, and J. Miller, 2008: Tropical Pacific forcing of North American medieval megadroughts: Testing the concept with an atmosphere model forced by coral-reconstructed SSTs. J. Climate, 21, 6175-6190.

—, A. Tzanova, and J. Nakamura, 2009: Drought in the southeastern United States: Causes, variability over the last millennium, and the potential for future hydroclimate change. J. Climate, 22, 5021-5045.

— M. Ting, C. Li, N. Naik, B. Cook, J. Nakamura, and H. Liu, 2013: Projections of declining surface-water availability for the southwestern United States. Nat. Climate Change, 3, 482-486.

Smith, T. M., and R. W. Reynolds, 2003: Extended reconstruction of global sea surface temperatures based on COADS data (1854-1997). J. Climate, 16, 1495-1510. 
Stahle, D. W., F. K. Fye, E. R. Cook, and R. D. Griffin, 2007: Tree-ring reconstructed megadroughts over North America since AD 1300. Climatic Change, 83, 133-149, doi:10.1007/ s10584-006-9171-x

Steinman, B. A., M. B. Abbott, M. E. Mann, N. D. Stansell, and B. P. Finney, 2012: 1,500 year quantitative reconstruction of winter precipitation in the Pacific Northwest. Proc. Natl. Acad. Sci. USA, 109, 11619-11623, doi:10.1073/pnas.1201083109.

St. George, S., D. Meko, and E. Cook, 2010: The seasonality of precipitation signals embedded within the North American Drought Atlas. Holocene, 20, 983-988, doi:10.1177/0959683610365937.

Stine, S., 1994: Extreme and persistent drought in California and Patagonia during mediaeval time. Nature, 369, 546-549, doi:10.1038/369546a0

Taylor, K. E., R. J. Stouffer, and G. A. Meehl, 2012: An overview of CMIP5 and the experiment design. Bull. Amer. Meteor. Soc., 93, 485-498.

Trenberth, K. E., and T. J. Hoar, 1996: The 1990-1995 El NiñoSouthern Oscillation event: Longest on record. Geophys. Res. Lett., 23, 57-60.
— and D. J. Shea, 2006: Atlantic hurricanes and natural variability in 2005. Geophys. Res. Lett., 33, L12704, doi:10.1029/ 2006GL026894.

USDA, cited 2013: U.S. drought 2012-13: Farm and food impacts. United States Department of Agriculture Economic Research Service. [Available online at http://www.ers.usda.gov/topics/ in-the-news/us-drought-2012-farm-and-food-impacts.aspx\#. UjBs7T-OmFM.]

Vicente-Serrano, S. M., S. Beguería, J. I. López-Moreno, M. Angulo, and A. El Kenawy, 2010: A new global 0.5 gridded dataset (1901-2006) of a multiscalar drought index: Comparison with current drought index datasets based on the Palmer Drought Severity Index. J. Hydrometeor., 11, 1033-1043.

Woodhouse, C. A., and J. T. Overpeck, 1998: 2000 years of drought variability in the central United States. Bull. Amer. Meteor. Soc., 79, 2693-2714.

, D. M. Meko, G. M. MacDonald, D. W. Stahle, and E. R. Cook, 2010: A 1,200-year perspective of 21st century drought in southwestern North America. Proc. Natl. Acad. Sci. USA, 107, $21283-21$ 288, doi:10.1073/pnas.0911197107. 